\title{
The European Journal of Ageing enters volume 8: and enjoys its consolidation
}

\author{
Hans-Werner Wahl · Dorly Deeg
}

Published online: 20 February 2011

(C) Springer-Verlag 2011

Is there a rule, when consolidation begins for a scientific journal? We are not aware of any. However, entering volume 8 in good shape after the regular presentation of 4 issues per year now since 2005 , as it is the case with the European Journal of Ageing, may be regarded as a clear supporting sign. Yes, we feel based on converging indicators that the European Journal of Ageing is near to the goal to be an established periodical for first-class research in social, behavioural and health related ageing in Europe and beyond.

First, we believe that the journal has something important to offer in terms of disciplinary and interdisciplinary ageing research and that volume 7 has been another convincing proof for this. For instance, we had two special sections both of which addressed key ageing research topics. The special section guest-edited by Mike Martin, Sherry Willis and Christina Röcke focused on midlife and included mostly psychological but also epidemiology and health related research. This section made it very clear how limited our knowledge regarding midlife and its role for old and very old age still is, but at the same time the papers also support the notion that we will never understand ageing, when conceptually and empirically life in the middle is not taken into better consideration. Gender gap in health expectancy has been the theme of the second special section guest-edited by Henrik Bronnum-Hansen and

H.-W. Wahl ( $($ )

Heidelberg University, Bergheimer Strasse 20,

69115 Heidelberg, Germany

e-mail: h.w.wahl@psychologie.uni-heidelberg.de

D. Deeg

VU University Medical Centre, LASA,

Van der Boechorststraat 7, 1081 BT Amsterdam,

The Netherlands
Berhard Jeune. As has been shown in this collection of papers coming out of a REVES (Réseau Espérance de Vie en Santé) meeting in 2009 in Copenhagen, the so-called male-female health-survival paradox (men have higher death rates than women, but women do worse with regard to disability related outcomes) still needs more research, for instance targeting the magnitude of the gender gap and treating mortality and morbidity in tandem in order to better understand more comprehensively the dynamics behind the gap. In addition, we saw in issue 4 of volume 7 the first contribution to our new section "Methodology issues in ageing research" (van Nes et al. 2010) targeting language differences in qualitative research, an issue of much importance for a region highly active in ageing research (including qualitative work), but at the same time operating in many languages, i.e., a now 27 member Europe. As is argued in the article, the generally preferred "reduction" to English language in cross-country qualitative research seems to have its limits and the way out is far from trivial and deserves much more research investments. We are also happy that we were able to contribute with research published in the European Journal of Ageing to ongoing key themes of the international ageing research literature such as distance-to-death and end-of-life related research (Aaltonen et al. 2010; Kotter-Grühn et al. 2010), driving forces of retirement incomes (Hershey et al. 2010), disability prevention issues (Daniels et al. 2010) and the interrelations between socio-structural variables and health (Schöllgen et al. 2010). The 5 most cited papers within the recent 90 days were two from the area of social gerontology (de Jong Gierveld and van Tilburg 2010; 223 downloads; Dykstra, 2009; 186 downloads), followed by two behavioural papers (Allemand et al. 2010; 152 downloads; Jopp and Schmitt 2010; 143 downloads) and a biodemographic paper (Oksuzyan et al. 2010; 143 downloads). 
Second, we have an impact factor since 2010, based on citations in the year 2009, which amounts to 0.608. This is a good beginning, so we believe, as it locates the European Journal of Ageing at number 23 within the 26 worldwide ageing journals which have an impact factor. When citations from one article to another article in the same journal are excluded, however, the European Journal of Ageing ranks nicely in the middle at rank17. Our own preliminary calculation of the journal's impact factor for 2010 makes it highly likely that we have surpassed the threshold of 1.0. Let's see what the official next calculation will bring, but there is obvious reason that the journal's papers are on a good track in terms of being cited by other scholars.

Third, the number of incoming papers has steadily increased during the last 5 years and has risen from 47 (2005) to 85 (2010). Of course, this is still only about a quarter of the submitted work as compared to world-class ageing journals such as the Journals of Gerontology or The Gerontologist, but these journals are operating now for 65 years. In any case, the large number of submissions implied that fewer submitted manuscripts can make it to publication. At the top of the countries, from which papers were submitted in 2010 were the following (five or more papers): The Netherlands (11), Spain (9), Sweden (9), the U.S. (5) and Germany (5). The countries from which manuscripts were submitted numbered 27, 17 of which were from the European sphere.

Fourth, we are in the process of refreshing and rearranging our editorial board. For one, a decision has been made in our last editorial board meeting to integrate the consulting editors into the regular editorial board. Also, we have asked our editorial board members to nominate earlystage researchers, who may step in for them in the very near future. This process has come now nearly to an end and will result in considerable replacement in all sections of our editorial board. The outcome will be seen in issue 2 of this year. At this stage, we would like to extend our gratitude to all editorial board members who are leaving the board for their commitment to our Journal from the beginning of its existence.

Now, what's ahead of us? We are in the process of confirming commitments for our "Critical Positions in Ageing Research" section, for which we hope to have at least one contribution in volume 8. In addition, we will continue our policy of going for special sections, one of which is in the planning/production stage targeting issues of care research. We will of course also use the forthcoming conference of the International Association of Gerontology and Geriatrics (European Region) in April 2011 in Bologna to advertise the journal.

Finally, we would like to thank the journal's publisher, Springer Verlag, particular Evelien Bakker, for the excellent support provided to nurture the journal's growth. This kind of backbone makes it extra rewarding for us to engage for the journal.

\section{References}

Aaltonen M, Forma L, Rissanen P, Raitanen J, Jylhä M (2010) Transitions in health and social service system at the end of life. Eur J Ageing 7(2):91-100

Allemand M, Gomez V, Jackson JJ (2010) Personality trait development in midlife: exploring the impact of psychological turning points. Eur J Ageing 7(3):147-155

Daniels R, Metzelthin S, van Rossum E, de Witte L, van den Heuvel $\mathrm{W}$ (2010) Interventions to prevent disability in frail communitydwelling older persons: an overview. Eur J Ageing 7(1):37-55

de Jong Gierveld J, van Tilburg T (2010) The De Jong Gierveld short scales for emotional and social loneliness: tested on data from 7 countries in the UN generations and gender surveys. Eur $\mathbf{J}$ Ageing 7(2):121-130

Dykstra PA (2009) Older adult loneliness: myths and realities. Eur J Ageing 6(2):91-100

Hershey DA, Henkens K, van Dalen HP (2010) What drives retirement income worries in Europe? A multilevel analysis. Eur J Ageing 7(4):301-311

Jopp DS, Schmitt M (2010) Dealing with negative life events: differential effects of personal resources, coping strategies, and control beliefs. Eur J Ageing 7(3):167-180

Kotter-Grühn D, Grühn D, Smith J (2010) Predicting one's own death: the relationship between subjective and objective nearness to death in very old age. Eur J Ageing 7(4):293-300

Oksuzyan A, Brønnum-Hansen H, Jeune B (2010) Gender gap in health expectancy. Eur J Ageing 7(4):213-218

Schöllgen I, Huxhold O, Tesch-Römer C (2010) Socioeconomic status and health in the second half of life: findings from the German Ageing Survey. Eur J Ageing 7(1):12-28

van Nes F, Abma T, Jonsson H, Deeg D (2010) Language differences in qualitative research: is meaning lost in translation? Eur $\mathbf{J}$ Ageing 7(4):313-316 